Int. J. Electrochem. Sci., 14 (2019) 7773 - 7789

\title{
Multi-physics Simulation of the Surface Polishing Effect During Electrochemical Machining
}

\author{
Weidong Liu, Sansan Ao, Zhen Luo*
}

School of Materials Science and Engineering, Tianjin University, Tianjin 300350, China.

*E-mail: $\underline{\text { lz tju@163.com }}$

doi: $10.20964 / 2019.08 .91$

Received: 18 April 2019 / Accepted: 4 June 2019 / Published: 30 June 2019

Electrochemical machining (ECM) is a widely used non-traditional machining technology. In addition to excellent shaping performance, ECM can generate a smooth surface finish. However, experimental investigations into the surface polishing mechanism of ECM are extremely challenging. To understand this microscale mechanism more deeply, we developed a novel multi-physics model for a numerical simulation. The model accounts for the major factors involved in ECM, including the electric field, flow field, ion transfer, electrode reaction kinetics, and anodic shape evolution. Based on this model, we investigated the effects of applied potential and flow speed on surface polishing. Furthermore, we studied the effect of the material's microstructure on surface polishing in ECM by setting position-dependent equilibrium potentials as boundary conditions. Our results show that the formation of an anodic supersaturated film, which is affected by the applied potential and flow speed, plays an important role in surface polishing.

Keywords: Multi-physics simulation; surface polishing; electrochemical machining;

\section{FULL TEXT}

(C) 2019 The Authors. Published by ESG (www.electrochemsci.org). This article is an open access article distributed under the terms and conditions of the Creative Commons Attribution license (http://creativecommons.org/licenses/by/4.0/). 